\title{
Siofor influence on the process of lipid peroxidation and antioxidant status at patients with metabolic syndrome
}

\author{
Elena N. Chernysheva, T.N. Panova
}

Astrakhan State Medical Academy, Astrakhan, Russia

Accepted 25 September 2014

Original Text @ Chernysheva E.N., Panova T.N., 2013, published in Saratov Journal of Medical Scientific Research 2013; 9(4): 744-752.

\begin{abstract}
The purpose of the work is to research siofor influence (metformin) on the activity of the process of lipid peroxidation and antioxidant activity of blood serum at patients with metabolic syndrome. Material and Methods -62 patients with metabolic syndrome at the age from 30 till 60 were examined and treated by siofor ( $1700 \mathrm{mg}$ per day) during a year. The process of lipid peroxidation was studied due to the level of lipid hydroperoxide of blood serum. Antioxidant capacity was based on the antioxidant reaction in the blood serum with definite number of exogenic hydrogen dioxide (mkmole/l) with the method of enzyme-linked immunosorbent assay (ELISA). Results Intensification of process of lipid peroxidation has been observed at patients with metabolic syndrome - the level of lipid hydroperoxide of blood serum has been $2.9(1.9,3.9) \mathrm{mkM}$ (presented as median and interquartile range), antioxidant activity of blood serum has been decreased - $276.4(239.0,379.9)$ mkmole/l. In 12 months of siofor intake hydroperoxide level has been decreased till 1.1 (0.8, 1.9$) \mathrm{mkM}$, but antioxidant activity has been increased and amounted $320.0(278.9,334.3)$ mkmole/l. Conclusion - Siofor has been proved to be a highly effective medicine for correction of process of lipid peroxidation and for improvement of antioxidant activity of blood serum at patients with metabolic syndrome.
\end{abstract}

Keywords: siofor intake, lipid peroxidation, antioxidant activity, metabolic syndrome

Cite as Chernysheva EN, Panova TN. Siofor influence on the process of lipid peroxidation and antioxidant status at patients with metabolic syndrome. Russian Open Medical Journal 2014; 3: 0402.

Correspondence to Elena N. Chernysheva. Phone: +7 (8512) 735554. E-mail: lena.chernysheva@inbox.ru

\section{Introduction}

Metabolic syndrome (MS) is a collective term; it unites a group of diseases and pathologic conditions of the same origin [1]. Metabolic syndrome is a common clinical implication; in the average every $5^{\text {th }}$ adult person in developed countries has the syndrome [2]. Almost all components of the MS are independent risk factors of cardiovascular failures developing, and a complex of several components significantly increases the risk of their progress. MS is associated with a significant increase of an ischemic heart disease, especially among men after 45 years and women over 55 years old [3]. In the research performed by the scientific center there had been revealed that $62 \%$ of patients with MS had a I degree AH (arterial hypertension) and 30\% - all degree $\mathrm{AH}$, this goes with a circadian BP rhythm defect and concentric hypertrophy of a left ventricle [4]. Patients with MS have a high risk of type 2 diabetes developing. According to World Health Organization (WHO) estimates the number of such patients in the world will go beyond 300 million people till 2025 , and from $92 \%$ to $97 \%$ of all cases will include type 2 diabetes, which imparts the character of a pandemia to the disease [5].

The basic pathogenic component of the MS is an insulin resistance (IR) [6]. Nitrogen oxide provides a physiological smoothmuscle cell proliferation and reduces damaging effect of lipid peroxidation (LPO) on a vessel wall. But in an insulin resistance conditions a nitrogen oxide synthesis in a vessel wall is defected. As a result, an endothelial dysfunction is developed, which may cause atherosclerotic lesions in vessels [7]. Besides, in a number of studies there was displayed that LPO in patients with MS effects on a structural-functional vessels condition and endothelium function, metabolism. Free radicals change apoprotein B structure, it causes producing oxidized low density lipoproteins which damage vessel endothelium [8]. This means that a high activity of a LPO processes in patients with MS leads to appearing and progressing of a cardiovascular pathology. IR causes compensatory hyperinsulinemia which increases the activity of a sympathetic nervous system and free radicals producing caused by catecholamines. To reduce IR Siofor (Metformin) medication was used. This medication is from the category of biguanides, stimulates tissue sensitization to insulin, and, probably, effects positively on LPO processes. In view of the foregoing the aim of the study is formed.

The research aimed to study an effect of Siofor (Metformin) on the activity of LPO process and antioxidant potency of a blood serum in patients with metabolic syndrome.

\section{Material and Methods}

The MS diagnostics is based on criteria suggested by experts of Russian Society of Cardiology (2009). The main criterion is waist circumference at females $>80 \mathrm{~cm}$ and $>94 \mathrm{~cm}$ at males. Additional features are following:

- arterial tension is $\geq 130 / 85 \mathrm{mmHg}$,

- increase of blood triglyceride level $\geq 1.7 \mathrm{mmol} / \mathrm{l}$, 
- decrease of high density lipoprotein cholesterol $<1.0 \mathrm{mmol} / \mathrm{l}$ at males and $<1.2 \mathrm{mmol} / \mathrm{l}$ at females,

- increase of low density lipoprotein cholesterol $>3.0 \mathrm{mmol} / \mathrm{l}$,

- fasting hyperglycemia (fasting glucose in blood plasma $\geq 6.1$ $\mathrm{mmol} / \mathrm{l}$ ),

- impaired glucose tolerance (glucose in blood plasma in 2 hours after glucose loading in the range of $\geq 7.8 \mathrm{mmol} / \mathrm{l}$ and $\leq 11.1 \mathrm{mmol} / \mathrm{l})$.

The presence of a central obesity and two additional criteria at a patient is the ground of a MS diagnostics.

Exclusionary for study were:

- age over 60 years old and younger than 30 years,

- active chronic diseases,

- hard uncontrolled arterial hypertension, active autoimmune diseases,

- blood system diseases,

- acute bacterial and virus infections for recent 3 months,

- malignant tumors,

- pregnancy,

- type 1 diabetes decompensation,

- hypothyroidism,

- thyrotoxicosis,

- taking glucocorticoids,

- surgical treatment earlier than 6 months ago.

At first we examined 70 persons with MS at the age from 30 to 60 years $(49.00(41.00,54.00)$ years; data presented as median interquartile range) -25 (62.5\%) men and 15 (37.5\%) women. 62 patients had not changed their principles of taking medications till the study finished (in 12 months) - 41 (66\%) males and 21 (34\%) females of $48(39.0,53.0)$ years. All of the patients agreed to be in for the research.

The control group included 70 persons matched with the patients without MS features in age $(47.0(40.0,52.0)$ years $)$ and sex (40 males $-57.1 \%$ and 30 females $-42.9 \%$ ).

Examination report included anthropometric research (body height, body weight), waist circumference (WC) and hip circumference $(\mathrm{HC})$, waist-to-hip-ratio (WHR), body mass index (BMI) and biochemical blood test performed after 12-hours fasting. Carbohydrate metabolism research included fasting glucose test, insulin level test in a blood serum using Insulin AccuBind Elisa kit by the EIA method, IR index (HOMA-IR) was calculated according to the formula:

glucose $(\mathrm{mmol} / \mathrm{l}) \mathrm{x}$ insulin $(\mathrm{mcU} / \mathrm{ml}) / 22.5$.

An increase of this parameter more than 2.77 displays the IR. Arterial hypertension was detected by office measuring of arterial tension using Korotkov's method, according to recommendations of Russian Society of Cardiology.

Lipid spectrum of the serum was estimated by total cholesterol level (TCL), triglycerids, high density lipoprotein cholesterol (HDLC), low density lipoprotein cholesterol (LDLC). Extra low density lipoprotein cholesterol (ELDLC) was calculated by the Friedwald's formula: $E L D L C=T C L-L D L C-H D L C$. Atherogenic index (AI) was calculated using the formula: $A=T C L-H D L C / H D L C$. To study LPO process there was used Lipid Hydroperoxide (LPO) Assay Kit - hydroperoxide lipids level was tested in blood serum by EIA. Antioxidant system condition was evaluated by the EIA method using ImAnOx (Tas/Tac) Kit. Determining of an antioxidant capability is based on antioxidants response, which is in the sample with a certain amount of exogenic hydrogen dioxide $\left(\mathrm{H}_{2} \mathrm{O}_{2}\right)$. Antioxidants in the sample eliminate some amount of hydrogen dioxide. The rest of $\mathrm{H}_{2} \mathrm{O}_{2}$ is determined by photometric method. Antioxidant activity: $<280 \mathrm{mmol} / \mathrm{l}-$ low, $280-320 \mathrm{mmol} / \mathrm{l}$ - medium, >320 $\mathrm{mmol} / \mathrm{l}$ - high.

Comparative characteristics of the patients with MS and the control group are presented in Table 1.

All of the patients were given a dietary guidance: feeding should be frequent, in small portions with no more than $1500 \mathrm{kcal}$ per day; the last meal -1.5 hours before bedtime. The base of the meals were low-glycemic complex carbohydrate, they should be $50-60 \%$ of nutrition value. Besides, the patients were instructed about keeping proper hours with dietary habits changing and regular physical exercises. The treatment using Siofor (BerlinChemie, Germany) was started from $500 \mathrm{mg} /$ day during a week (to minimize gastro-intestinal tract side effects), then the doze was increased up to 1700 (850 mg twice a day) $\mathrm{mg} /$ day. The patients had been taking the medication for a year, with control after 3,6 , 9 and 12 months.

Statistical analysis of the results was performed by IBM using Statistica 7.0 (StatSoft, USA). Quantitative parameters were checked using Shapiro-Wilk test. The distribution number differs from normal parameters, so, the data are presented as Me $(L Q, U Q)$, where: Me is mediana; $L Q$ is low quartile; $U Q$ is upper quartile. Group differences were estimated by Mann-Whitney non-parametric tests. The results were statistically significant at significance level of $P<0.05$.

\section{Results}

As we can see from the Table 2, there are statistically significant values in all studied parameters between the patients with MS and the control group, $\mathrm{P}<0.05$.

Table 1. Comparative characteristics of the patients with metabolic syndrome and control group

\begin{tabular}{lcc}
\hline \multicolumn{1}{c}{ Parameters } & $\begin{array}{c}\text { Control group } \\
(n=70)\end{array}$ & $\begin{array}{c}\text { Patients with } \\
\text { metabolic syndrome } \\
(n=62)\end{array}$ \\
\hline BMI, kg/m ${ }^{2}$ & $24.5(21.3,24.8)$ & $35.0(32.1,41.3)^{*}$ \\
Waist circumference, cm & $88.0(76.0,92.0)$ & $122.0(113.0,135.0)^{*}$ \\
Hip circumference, cm & $95.0(93.0,98.0)$ & $113.5(108.0,134.5)^{*}$ \\
SBP, mmHg & $118.0(110.0,123.0)$ & $151.0(147.5,155.0)^{*}$ \\
DBP, mmHg & $70.0(65.0,74.0)$ & $95.0(93.5,99.5)^{*}$ \\
Glucose, mmol/I & $4.7(4.5,4.9)$ & $5.9(5.5,6.2)^{*}$ \\
Insulin, mcU/ml & $10.13(8.9,11.6)$ & $39.9(31.9,53.5)^{*}$ \\
HOMA- IR & $2.1(1.8,2.5)$ & $9.4(7.6,13.5)^{*}$ \\
Total cholesterol, mmol/I & $4.5(4.1,4.8)$ & $6.9(6.3,7.3)^{*}$ \\
Triglycerides, mmol/I & $1.33(1.2,1.5)$ & $3.1(2.2,3.6)^{*}$ \\
LDLC, mmol/l & $2.3(2.1,2.4)$ & $4.2(3.8,4.7)^{*}$ \\
HDLC, mmol/l & $1.6(1.4,1.7)$ & $1.05(1.0,1.5)^{*}$ \\
ELDLC, mmol/l & $0.6(0.6,0.7)$ & $1.4(1.0,1.7)^{*}$ \\
Atherogenic index & $1.8(1.8,1.9)$ & $4.2(3.5,5.1)^{*}$ \\
\hline
\end{tabular}

SBP, systolic blood pressure; DBP, diastolic blood pressure.

${ }^{*} \mathrm{P}<0.05$ by comparison of the research group and the control group.

Table 2. Comparative characteristics of the patients with metabolic syndrome and control group

\begin{tabular}{ccc}
\hline \multicolumn{1}{c}{ Parameters } & $\begin{array}{c}\text { Control group } \\
(n=70)\end{array}$ & $\begin{array}{c}\text { Patients with } \\
\text { metabolic syndrome } \\
(n=62)\end{array}$ \\
\hline Lipid hydroperoxides, $\mu \mathrm{M}$ & $0.5(0.5,0.6)$ & $2.9(1.9,3.9))^{*}$ \\
Antioxidant activity, $\mu \mathrm{M} / \mathrm{I}$ & $304.5(296.2,311.7)$ & $276.4(239.0,379.9))^{*}$ \\
\hline
\end{tabular}

$* \mathrm{P}<0.05$ by comparison of the research group and the control group. 
Table 3. Dynamics of parameters of lipid peroxidation processes and antioxidant activity of blood serum at the patients with metabolic syndrome on the background of Siofor treatment

\begin{tabular}{lcc}
\hline Observational period & $\begin{array}{c}\text { Lipid hydroperoxides, } \\
\mu M\end{array}$ & $\begin{array}{c}\text { Antioxidant activity, } \\
\text { MKM/I }\end{array}$ \\
\hline Before treatment & $2.9(1.9,3.9)$ & $276.4(239.0,379.9)$ \\
After 3 months & $2.8(1.9,3.7)$ & $279.0(245.0,375.6)$ \\
After 6 months & $1.9(1.5,3.1)^{*}$ & $302.3(254.1,370.0)^{*}$ \\
After 9 months & $1.7(1.3,2.9)^{*}$ & $309.0(247.5,356.2)^{*}$ \\
After 12 months & $1.1(0.8,1.9)^{*}$ & $320.0(278.9,334.3)^{*}$
\end{tabular}

* $\mathrm{P}<0.05$, statistical significance comparing with the parameters before treatment.

Performed tests displayed that LPO processes are intensified at the patients with MS - lipid hydrogen dioxide level almost 6 times higher then in the group of control. Antioxidant activity of blood serum of the patients with MS was reduced.

Analysis of the dynamics of these parameters on the background of Metformin taking displays its efficiency (Table 3), although statistically significant differences in the studied parameters appear only in 6 month of taking the medication.

It was found out that a hydrogen dioxide level had decreased almost 3 times during a year after medication taking $-1.1(0.8$, 1.9) $\mu \mathrm{M}$. Antioxidant activity increases, and achieves physiological values after 6 months - $302.3(254.1,370.0) \mu \mathrm{M} / \mathrm{l}$.

In our recent studies there was a strong correlative relationship between lipid hydroperoxides and BMI ( $r=+0.77$, $\mathrm{P}<0.05$ ) [9]. We divided all of the patients with MS into groups:

1) patients with BMI from 30.0 to 39.9 (I-II degree of obesity) 32 patients $(51,6 \%)$;

2) patients with BMI from 40 and over (III and higher degree of obesity) -30 patients $(48,4 \%)$.

In the $1^{\text {st }}$ group BMI was $34.1(32.3,37.6)$, in the $2^{\text {nd }}$ group 41.3 (40.5, 43.6); index HOMA-IR $8.8(7.1,14.5)$ and 10.0 (8.9, 16.4) respectively, $\mathrm{P}<0.05$. In the $1^{\text {st }}$ group lipid hydroperoxides level in blood serum was $2.7(2.2,3.5) \mu \mathrm{M}$, in the $2^{\text {nd }}$ one -3.4 $(2.9,4.3) \mu \mathrm{M}, \mathrm{P}<0.05$. Antioxidant activity in the $1^{\text {st }}$ group was $343.2(290.5,363.7) \mu \mathrm{M} / \mathrm{I}$, in the $2^{\text {nd }}$ group $-263.1(234.5,290.4)$ $\mu \mathrm{M} / \mathrm{l}, \mathrm{P}<0.05$.

\section{Discussion}

The results we got show that at the patients with MS LPO and antioxidant activity of blood serum disorders caused by IR evidence. MS in IR conditions is characterized by an increase of sympatho-adrenal system activity, which leads LPO processes activation. Whereas LPO which is caused by a complex reduction of antioxidant system and increased synthesis of free radicals at the patients with MS, is one of important reasons of IR support. So, there is a vicious circle. In this situation Siofor (Metformin) prescription is reasonable, because it reduces IR due to restoration of tissue sensitization to insulin by the growth of the amount of affinity receptors, through a stimulation of tyrosine kinase the activity of insulin receptors increases, expression and transposition of glucose transporters from intracellular store into cell membrane. All of these processes lead to an increase of glucose uptake by insulin target-organs: liver, skeletal muscles, fatty tissue. Besides, according to recent research data, the medication can trap free radicals or reduce their level by slowing down of intercellular forming of superoxide radicals $\left(\mathrm{O}^{2-}\right)$, the major source of which is nitrogen oxides (NOX) acidification.
On the background of Metformin there was a significant reducing of lipid hydroperoxides and normalization of endogenic antioxidant background: after 12 months of Metformin taking hydroperoxides level decreased to $1.1(0.8,1.9) \mu \mathrm{M}$, and antioxidant activity increased to $320.0(278.9,334.3) \mu \mathrm{M} / \mathrm{l}$. This is the ground to recommend Metformin as a medication for corrective treatment of LPO disorders and antioxidant status at MS.

Correlative analysis displayed that there is a strong direct connection between lipid hydroperoxides and BMI ( $r=+0.77$, $P<0.05)$. This may be explained as follows: in the recent studies we found out that IR is intensified when BMI increases [10]. The IR worsening leads to the LPO intensifying and increasing of lipid hydroperoxides.

It is an interesting fact about antioxidant activity of blood serum: it is higher at the patients with MS and I-II degree of obesity, and lower - at III and higher degree of obesity. This is evident that as the obesity is intensified LPO products are produced faster, and, in order to balance these changes, antioxidant activity increases, but on a certain stage it is wasted, adaptation failure and low antioxidant activity.

\section{Conclusion}

Siofor (Metformin) medication is effective in correcting of LPO processes and restoration of antioxidant activity in blood serum at the patients with metabolic syndrome.

\section{Conflict of interests}

The study is performed as a scientific research (State registration number 01201155614)

\section{References}

1. Alessi MC, Juhan-Vague I. PAl-1 and the metabolic syndrome: the links, causes and consequences. Arterioscler Thromb Vasc Biol 2006; 26(10): 2200-2207. (doi: 10.1161/01.ATV.0000242905.41404.68) (PMID: 16931789)

2. Daskalopoulou SS, Mikhailidis DP, Elisaf M. Prevention and treatment of the metabolic syndrome. Angiology 2004; 55(6): 589-612. (PMID: 15547646) (doi: 10.1177/00033197040550i601)

3. Hong $\mathrm{Y}$, Jin $\mathrm{X}$, Mo J, Lin HM, Duan $\mathrm{Y}, \mathrm{Pu} \mathrm{M}$, et al. Metabolic syndrome, its preeminent clusters, incident coronary heart disease and all-cause mortality: results of prospective analysis for the atherosclerosis risk in communities study. J Intern Med 2007; 262(1): 113-122. (PMID: 17598819) (doi: 10.1111/j.1365-2796.2007.01781.x)

4. Mamedov MN, Gorbunov VM, Kiseleva NV, Oganov RG. Structuralfunctional changes of myocardium and hemody-namic disturbances in patients with metabolic syndrome: contribution of arterial hypertension in formation of total coronary risk. Kardiologiia 2005; 45(11): 11-16. Russian (PMID: 16353058)

5. Caballero AE. Endothelial dysfunction in obesity and insulin resistance: a road to diabetes and heart disease. Obes Res 2003; 11(11): 12781289. (PMID: 14627747) (doi: 10.1038/oby.2003.174)

6. Aleksandrov OV, Alehina RM, Grigor'eva SP. Metabolic syndrome. Ros Med Zhurn 2006; (6): 50-54. Russian

7. Oganov RG, Mamedova MN. School of diagnostics and treatment of metabolic syndrome. Moscow, Russia: Med. kniga, 2007. Russian

8. Rojtberg GE. Metabolic syndrome. Moscow, Russia: MED-M 54 pressinform, 2007. Russian

9. Chernysheva EN, Panova TN, Donskaya MG. The process of lipid peroxidation and senilism due metabolic syndrome. Kubanskii nauchnyi meditsinskii vestnik 2013; (1): 181-184. Russian 
10. Chernysheva EN, Panova TN, Balashov VI. Study of a body mass index, arterial hypertention, blood insulin level at patients with insulin resistance syndrome. Estestvennye nauki 2004; (8): 102-104. Russian

Authors:

Elena N. Chernysheva - MD, PhD, PostDoc, Department of Hospital Therapy with the Course of Functional Diagnostics, Astrakhan State Medical Academy, Astrakhan, Russia;

T.N. Panova - MD, DSc, Professor, Department of Hospital Therapy with the Course of Functional Diagnostics, Astrakhan State Medical Academy, Astrakhan, Russia. 